\title{
Early attentional difficulties were associated with later academic failure and arrests
}

Fergusson DM, Lynskey MT, Horwood LJ. Attentional difficulties in middle childhood and psychosocial outcomes in young adulthood. J Child Psychol Psychiat 1997 Sep;38:633-44.

\section{Question}

Is there an association between attentional difficulties at 8 years of age and psychosocial outcomes at 18 years of age?

\section{Design}

Cohort analytic study (Christchurch Health and Development Study).

\section{Setting}

Urban region of New Zealand.

\section{Participants}

A birth cohort of 969 children

\section{Assessment of risk factors}

At 8 years of age maternal and teacher reports of the child's inattentive, restless, or hyperactive behaviours were obtained using an instrument that combined the Rutter and Conners parent and teacher questionnaires. A scale score was created and cut points divided the sample into 5 class intervals of inattentive behaviour (1-50, 51-75, 76-90, 91-95, and 96-100 centiles). Data on conduct problems and demographic, school, educational, and family factors were also collected.

\section{Main outcome measures}

Blinded assessment of measures of educational achievement (scoring below 12 year old average on Burt test at 18 years, leav- ing school before the age of 16 , leaving school without qualifications, and School Certificate passes [ $\geqslant$ grade C]), juvenile offending (frequent offending [ $\geqslant 8$ times], arrests, and convictions), and substance use (nicotine dependence, and alcohol and other substances abuse/dependence) at 18 years of age.

\begin{abstract}
Main results
After adjustment for increasing social disadvantage, higher exposure to family and childhood problems, lower exposure to early preschool education, lower IQ at 8 years of age, and higher rates of conduct problems at 8 years of age, attentional difficulties were related to later academic success but not to later juvenile offending (except for arrests) or substance use behaviours (table). With increasing attentional difficulties there was also reduced success in School Certificate examinations (comparison of the lowest centile of attentional difficulties with the highest, a mean of $3.8 v 2.6$ passes, $\mathrm{p}<0.001)$.
\end{abstract}

\section{Conclusion}

After adjustment for confounding factors, early attentional difficulties were related to later academic success and arrests but not to other juvenile offending or substance use behaviours.

Sources of funding: Health Research Council of New Zealand; National Child Health Research Foundation; Canterbury Medical Research Foundation; New Zealand Lottery Grants Board.

For correspondence: Dr D M Fergusson, Christchurch Health and Development Study, Christchurch School of Medicine, PO Box 4345, Christchurch, New Zealand. Fax +6433720405.

Odds ratios (95\% confidence intervals) for higher centile groups on the measure of attentional problems in comparison with the group with the lowest levels of attentional problems after adjustment for covariates*

\begin{tabular}{|c|c|c|c|c|}
\hline Outcomes & Group 2 v Group 1 & Group 3 v Group 1 & Group 4 v Group 1 & Group 5 v Group 1 \\
\hline $\begin{array}{l}\text { Below } 12 \text { year old average on Burt reading } \\
\text { test at age } 18 \text { years }\end{array}$ & $1.3(1.0$ to 1.6$)$ & $1.6(1.0$ to 2.6$)$ & $2.0(1.0$ to 4.1$)$ & $2.6(1.0$ to 6.6$)$ \\
\hline Left school before age of 16 & $1.5(1.2$ to 2.0$)$ & $2.2(1.3$ to 3.9$)$ & $3.3(1.4$ to 7.9$)$ & $4.9(1.6$ to 15.6$)$ \\
\hline Left school without qualifications & $1.5(1.3$ to 1.8$)$ & $2.3(1.6$ to 3.3$)$ & $3.4(2.0$ to 6.1$)$ & $5.2(2.4$ to 11.0$)$ \\
\hline Arrested & $1.4(1.0$ to 1.9$)$ & $1.9(1.1$ to 3.4$)$ & $2.6(1.1$ to 6.3$)$ & $3.6(1.1$ to 11.7$)$ \\
\hline
\end{tabular}

*Data provided by the authors. Group centiles on attentional problems: group 1, 1-50; group 2, 51-75; group 3, 76-90; group 4, 91-95; group 5, 96-100.

\section{Commentary}

The study of attention in elementary school years gives further support to the meaningful contribution that early function makes to later adjustment. Several important observations arise from the study by Fergusson et al. For many years, parent and teacher opinions were viewed as playing the part of self fulfilling prophecies. The data reported in this study do not support this possibility. If it were true, one would not expect social factors to eliminate the influence of early inattention on only some later outcomes. Judiciously, the investigators controlled for social factors in this study of the effect of early inattention on later outcome. Only academic performance remained as an outcome predicted by early attentional difficulties, whereas anti- social behaviours did not. There is no reason to expect academic function to be more amenable to the effects of expectation than other behavioural repertories. From a developmental viewpoint, the results make perfect sense. Thus, there is clear merit in the identification of attentional problems in young children.

Early theories of reading disorders attributed a causal role to deficits of attention. ${ }^{1-4}$ This view has been neglected,although inefficient information processing as the neurophysiological basis of reading disorders has been suggested more recently. ${ }^{5}$ The findings raise the issue in a practical, clinical context. The challenge is to identify the specific nature of the attentional dysfunction and its clinical manifestations, and ultimately to generate guidelines for the identification of at risk children. This study has made a rich contribution to an important aspect of child development. As is often the case, it may be raising more questions than it answers.

Rachel G Klein, $\mathrm{PhD}$ New York State Psychiatric Institute New York, New York, USA

1 Atkinson BP, Seunath OH. J Learn Disabil 1973;6:569-73.

2 Dykman RA, Ackerman PT, Clements S, et al. In: Myklebust HR, editor. Progress in learning disabilities. Volume 2. New York: Grune \& Stratton, 1971:56-93.

3 Samuels SJ. J Educ Psychol 1967;58:337-42.

4 Santostefano S, Rutledge L, Randall D. Psychol Santostefano S, Rutledge
Schools 1965;2:57-62.

5 Merzenich MM, Jenkins WM, Johnston P, et al. Science 1996;271:77-81. 